\title{
Evasão em cursos a distância: um estudo aplicado na Universidade Corporativa da Secretaria da Fazenda do Estado da Bahia
}

\author{
Ricardo Alonso Gonzalez \\ Universidade Federal da Bahia (UFBA) \\ Janicleide Gonçalves do Nascimento \\ Universidade Corporativa (Sefaz/BA) \\ Luciana Barone Leite \\ Universidade Corporativa (Sefaz/BA)
}

Um dos desafios da administração pública moderna é manter o seu quadro de pessoal capacitado para desenvolver as suas funções com qualidade e prestar um melhor serviço à sociedade. A educação a distância (EaD) apresenta-se como uma alternativa. Contudo, traz consigo uma questão que precisa ser melhor compreendida: o alto índice de evasão. O objetivo deste artigo é investigar os determinantes da evasão nos cursos EaD oferecidos pela Universidade Corporativa da Secretaria da Fazenda do Estado da Bahia. Para tanto, desenvolveu-se um estudo quantitativo em uma amostra composta por 530 inscritos nos cursos EaD oferecidos no primeiro semestre do ano de 2014, buscando identificar, entre as variáveis carga horária do curso, gênero, idade, localização do inscrito e cargo, evidências que explicassem os índices de evasão observados. Os resultados, obtidos por meio de regressão logística múltipla, sugerem que a localização do indivíduo exerce influência significativa na evasão.

Palavras-chave: educação a distância, educação corporativa, evasão, administração pública, estudo de caso

[Artigo recebido em 3 de setembro de 2015. Aprovado em 28 de março de 2016.] 


\section{Evasión de la educación a distancia en la educación corporativa: un estudio aplicado en lo Departamento de Hacienda del Estado de Bahía}

Uno de los desafíos de la administración pública moderna es mantener a su personal capaz de llevar a cabo sus funciones con calidad para la sociedad. Educación a distancia (EaD) se presenta como una alternativa, sin embargo, trae consigo un problema que necesita ser mejor entendido: la alta tasa de deserción. El objetivo de este trabajo es investigar los factores determinantes de la evasión en los cursos EaD de la Universidad Corporativa de lo Departamento de Hacienda del Estado de Bahía. Para ello, ha desarrollado un estudio cuantitativo sobre una muestra de quinientos treinta inscritos en cursos EaD ofrecidos en el primer semestre de 2014 con el fin de identificar, entre los variables de la carga del curso, el género, la edad, la ubicación de domicilio y la posición, evidencias para explicar la deserción observada. Los resultados obtenidos mediante regresión logística múltipla sugieren que la localización de la persona ejerce una influencia significativa en la evasión.

Palabras-clave: educación a distancia, educación corporativa, evasión, administración pública, estudio de caso

\section{E-learning evasion in corporate education: an applied study at the Secretariat of Finance of the State of Bahia}

One of the challenges of modern public administration is to keep the staff able to carry out their functions with quality and provide better service to society. E-learning has been presented as an alternative, however, it brings an issue that needs to be better understood: the high dropout rate. This paper aims to investigate the determinants of evasion in e-learning courses of the Corporate University of the Secretariat of Finance of the State of Bahia. To achieve this goal, a quantitative study has been applied on a sample of five hundred thirty enrolled in e-learning courses offered in the first half of 2014 in order to identify, among the variables workload of the course, gender, age, location of the registered and his position, evidence to explain the dropout rate observed. The results obtained by means of multiple logistic regression suggest that the location of the individual exercises significant influence on evasion.

Keywords: distance education, corporate education, evasion, public administration, case study 


\section{Introdução}

O tema evasão na educação a distância não é novo, contudo, faz parte, ainda, de uma agenda de pesquisa a ser explorada. A questão central deste artigo é investigar a significância das variáveis carga horária do curso, gênero, idade, localização do participante (capital ou interior) e o cargo (carreira da Sefaz ou carreira administrativa) na explicação da taxa de evasão observada nos cursos a distância oferecidos pela Secretaria da Fazenda do Estado da Bahia (Sefaz/BA) aos seus servidores no primeiro semestre do ano de 2014 , que alcançou $37 \%$ do número de matriculados. Assume-se como hipóteses que maiores cargas horárias dos cursos, o cargo e a localização do aluno exercem influência significativa no índice de evasão, enquanto que o gênero e a idade não exerceriam influência significativa.

A educação a distância (EaD) é uma modalidade de ensino que utiliza as tecnologias da informação e comunicação (TIC), como a internet e as ferramentas de interação disponíveis nos ambientes virtuais de aprendizagem (AVA), como os fóruns, chats e hipertextos, gerando uma rede colaborativa que ultrapassa os limites físicos de uma sala de aula presencial, criando condições potenciais para a interação e o desenvolvimento de projetos comuns em diferentes tempos e espaços (PRETTO; PICANÇO, 2005).

O Decreto n 5.622 , de 19 de dezembro de 2005, caracteriza a educação a distância como um processo de ensino-aprendizagem realizado com mediação docente e que utiliza recursos didáticos sistematicamente organizados que são apresentados em diferentes suportes tecnológicos de informação e comunicação, os quais podem ser utilizados de forma isolada ou combinada.

Para a Universidade Corporativa da Secretaria da Fazenda do Estado da Bahia (UCS/ Sefaz), a EaD é "um processo de ensino-aprendizagem, mediado por tecnologias, no qual professores e alunos estão separados espacial e/ou temporalmente" (MoRAN, 2002, p. 1).

A Sefaz/BA optou pelo AVA operado pela plataforma Moodle, por se tratar de um software gratuito, de código aberto, que possibilita a realização de alterações em seu banco de dados de acordo com as necessidades da instituição, além da facilidade de uso, quantidade de ferramentas e capacidade de gerenciamento. Não há requisitos avançados para o uso do AVA da Sefaz, apenas ter acesso à internet e um navegador web.

Na formação em educação à distância, o formador é também um aprendiz em formação. Pois ainda estamos em um período embrionário, em que muitas possibilidades surgem, mas não há caminhos certos a seguir. Cada público, cada projeto possui uma necessidade diferente e, também por isso, ainda se está engatinhando na questão da formação em EaD (SANTOS, 2012, p. 41). 
Como principal característica, a EaD possui uma grande correlação entre a colaboração, a produção e o compartilhamento dos conhecimentos tácito e explícito ${ }^{1}$, ou seja, a sua produção de conhecimento busca priorizar a interação entre os conhecimentos dos alunos e professores, evidenciando sempre a coletividade, a troca de experiências e o trabalho em equipe nos seus processos de construção (RICCIO, 2005).

Por todas as suas características, a EaD, de acordo com Ramos (2000), vem sendo amplamente utilizada para a formação continuada de profissionais em diferentes áreas, gerando o processo chamado de virtualidade na educação, principalmente nas universidades corporativas, unidades voltadas para a educação permanente do quadro de funcionários das organizações públicas e privadas.

Além desta Introdução, o artigo é composto pelo Contexto, onde se relata o ambiente em que a pesquisa foi realizada; a Fundamentação teórica, explorando-se a literatura sobre evasão em cursos a distância; os Procedimentos metodológicos, onde se apresentam o modelo de análise proposto e as hipóteses testadas, a descrição da amostra, a forma de coleta de dados e a técnica estatística empregada; os resultados; e as considerações Finais, com uma proposta de agenda para pesquisa.

\section{Contexto}

A Sefaz/BA é uma instituição pública que possui uma universidade corporativa, cuja finalidade é promover, coordenar e executar as ações de capacitação, a formação dos seus servidores e a gestão do conhecimento, visando ao alcance das metas estratégicas da secretaria. Em um estado com dimensões territoriais de $657.295 \mathrm{~km}^{2}$, equivalente à extensão territorial da França, a EaD se constitui como um recurso indispensável para levar capacitação aos servidores que se encontram, principalmente, no interior do estado. Dados do primeiro semestre do ano de 2014 da Coordenação de Ensino a Distância (Ceadi), unidade da UCS/Sefaz responsável por gerir o programa de EaD na Sefaz/BA, apontam que metade dos inscritos nos cursos a distância situavam-se no interior do estado, assim como apontam, também, uma elevada taxa de evasão. Nesse sentido, buscam-se com este artigo evidências

\footnotetext{
${ }^{1}$ Tácito e explicito é uma distinção clássica dos tipos de conhecimento, principalmente quando se trata de conhecimento organizacional, fundada no trabalho seminal de Polanyi (1974). Por conhecimento tácito entende-se aquele que não é codificado. É associado a aptidões, habilidades e talentos particulares, difícil de ser compartilhado ou transferido. Advém, por exemplo, de situações vivenciadas pelo indivíduo no ambiente de trabalho, que não podem ser verbalizadas ou registradas. Por conhecimento explícito entende-se aquele que pode ser facilmente transferido, pois, encontra-se codificado e à disposição de todos. Trata-se do conhecimento que se encontra nos livros, manuais, projetos etc., podendo ser facilmente levado de um local para outro. Para aprofundamento sobre conhecimento tácito e explicito consultar Polanyi (1974), e Johnson (2011).
} 
que permitam explicar a alta taxa de evasão por meio das variáveis carga horária dos cursos, gênero, idade, localização dos inscritos - se na capital ou no interior do estado - e cargo ocupado - se de carreira da Sefaz ou cargos administrativos.

Na Sefaz/BA, as ações de capacitação são desenvolvidas por meio de uma universidade corporativa, criada por meio do Decreto estadual no 9.533/2005, que, por sua vez, subordina-se regimentalmente a uma superintendência, designada por Superintendência de Gestão Fazendária (SGF).

A SGF é composta por três diretorias: a Diretoria de Atendimento (Dirat), a Diretoria de Tecnologia da Informação (DTI) e a Universidade Corporativa (UCS/ Sefaz). Interessa compreender a UCS/Sefaz, que é integrada por cinco coordenações e um núcleo de gestão do conhecimento, sendo que uma das coordenações, a Ceadi, é voltada exclusivamente para implantar e desenvolver os treinamentos na modalidade de ensino a distância, conforme apresentado na Figura 1.

\section{Figura 1 - Organograma da UCS/Sefaz}

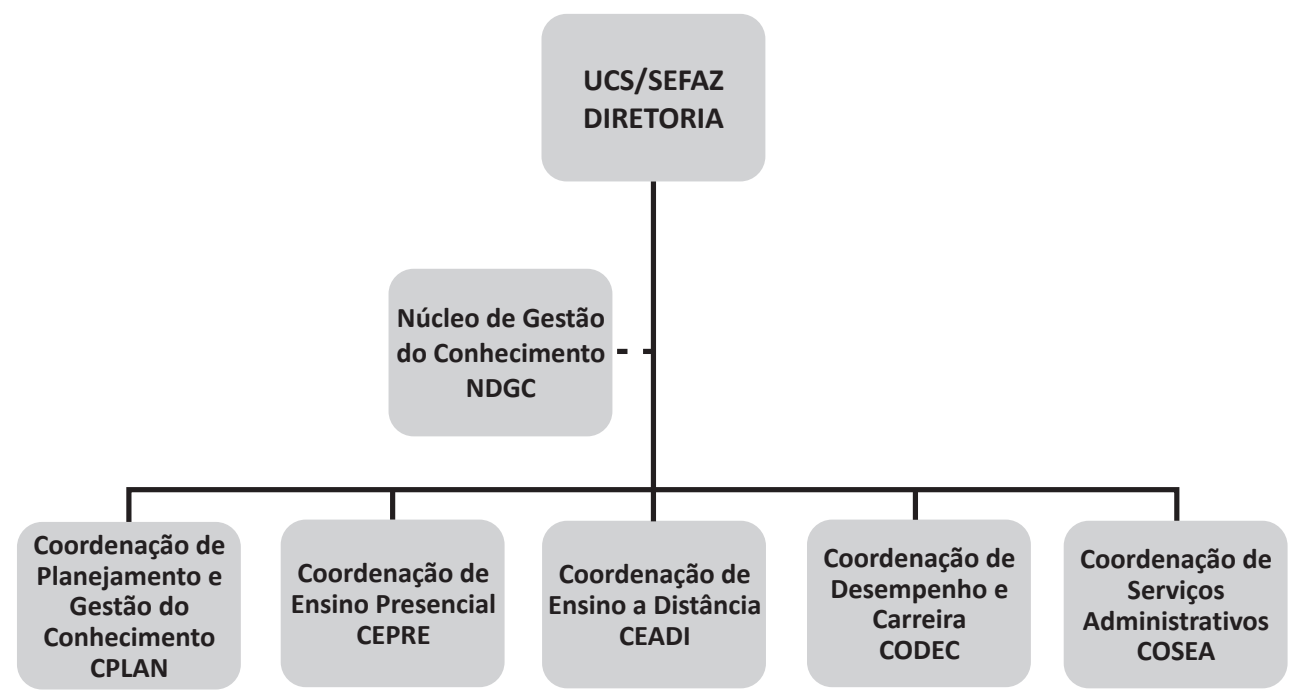

Fonte: Adaptado de Gonzalez e Silva (2013).

Os cursos oferecidos na modalidade a distância são agrupados em quatro áreas de conhecimento: a) administração, economia e finanças; b) conhecimentos gerais, habilidades e atitudes; c) contabilidade, auditoria e fiscalização; d) direito e legislação. O Quadro 1 apresenta a síntese das áreas de concentração dos cursos, o público alvo e a carga horária média dos cursos que compõem cada área de concentração. 
Quadro 1 - Síntese das áreas de concentração dos cursos EaD

\begin{tabular}{|l|l|l|}
\hline Área de concentração & $\begin{array}{l}\text { Carga horária } \\
\text { média }\end{array}$ & Público alvo \\
\hline Administração, economia e finanças & 60 & Todos \\
\hline $\begin{array}{l}\text { Conhecimentos gerais, habilidades e } \\
\text { atitudes }\end{array}$ & 20 & Todos \\
\hline Contabilidade, auditoria e fiscalização & 40 & $\begin{array}{l}\text { Auditor Fiscal } \\
\text { (AF), Agente de } \\
\text { Tributos estadu- } \\
\text { ais (ATE) }\end{array}$ \\
\hline Direito e legislação & 24 & AF, ATE \\
\hline
\end{tabular}

Fonte: Elaboração própria.

Cada área de concentração é formada por um portfólio de cursos. Atualmente esse portfólio conta com vinte e nove cursos que são oferecidos ao longo do ano ao seu público alvo. Os cursos a distância da Sefaz/BA são construídos internamente em quatro etapas, contadas após a definição do plano do curso, envolvendo: a) construção da apostila, que reúne todo o conteúdo; b) atividades de desenho instrucional e virtualização; c) aplicação de turma-piloto; e d) validação. Utilizandose o conceito de e-learnig (aprendizado eletrônico), os cursos a distância são totalmente realizados por meio do computador.

Todos os cursos são gratuitos, autoinstrucionais e exigem a realização de atividades avaliativas (fóruns e questionários) durante o seu percurso. As atividades são pré-programadas e o conteúdo é dividido em unidades que se complementam em uma linha de raciocínio direcionada aos objetivos de cada curso. O participante é certificado quando possui um aproveitamento superior a $60 \%$ em média ponderada entre as atividades avaliativas (40\%) e a participação no curso (60\%), essa última, atendendo a frequência mínima de cinquenta por cento da carga horária definida para o curso. Todos os participantes possuem apoio técnico da Ceadi, que realiza atividades de monitoria, sendo designado um monitor para cada turma com 30 participantes. Os cursos não possuem tutor em função da ausência de previsão legal para o exercício da atividade no âmbito da educação corporativa estadual.

Ao final de cada curso, o participante é convidado a avaliá-lo. Dessa forma, os cursos são pontuados segundo os critérios de planejamento (carga horária e coerência dos conteúdos com os objetivos), conteúdo (linguagem e atividades), interface gráfica (recursos e distribuição de textos), atendimento (apoio da monitoria e tempo de resposta) e autoavaliação (conhecimento agregado e motivação). É disponibilizado, também, um espaço livre para comentários. A média de pontuação 
dos cursos foi de 8,9, em uma escala que varia de 0 a 10, e os comentários são utilizados como base para o aprimoramento das novas versões desses cursos.

\section{Fundamentação teórica}

Alguns estudos recentes têm buscado identificar as motivações para a evasão dos cursos a distância, a exemplo de Bittencourt e Mercado (2014); Bizarria, Silvia e Carneiro (2014); Lacerda e Spíndola (2013); Martins et al. (2013); Almeida et al. (2013); Alves e Sales (2012); Zordan (2012); Silveira (2012); Netto, Guidotto e Santos (2012); Bruno-Faria e Franco (2011); Sales, Abbad e Rodrigues (2011); e Jorge et al. (2010), entre outros.

Bittencourt e Mercado (2014) investigaram as causas da evasão em turmas piloto do curso de Administração na Universidade Federal de Alagoas. Os achados de pesquisa evidenciaram que as principais causas da evasão relacionam-se a problemas endógenos à instituição, ou seja, fatores institucionais e didáticopedagógicos. Os autores associam fatores endógenos a "causas diretamente ligadas ao aluno quando está na instituição de ensino, como: atitude comportamental, motivos institucionais e requisitos didático-pedagógicos do curso" (BITTENCOURT; MerCAdo, 2014, p. 467).

Ainda segundo Bittencourt e Mercado (2014), as causas da evasão, considerandose seu caráter endógeno ou exógeno, podem ser dispostas conforme apresentado no Quadro 2.

Quadro 2 - Causas endógenas e exógenas da evasão dos cursos EaD

\begin{tabular}{|l|l|}
\hline Causas endógenas & Causas exógenas \\
\hline Atitude comportamental & Sócio-político-econômicas \\
\hline Didática dos professores & Apoio da instituição que trabalha \\
\hline Orientação da coordenação do curso & Valorização do diploma no mercado \\
\hline Motivação e incentivo por parte do tutor & Tempo para estudar \\
\hline Insatisfação com o tutor & Carga horária semanal de trabalho \\
\hline \multirow{3}{*}{ Contato com professores } & Deslocamento até polo de ensino \\
\cline { 2 - 2 } & Dificuldades de acesso à Internet \\
\cline { 2 - 2 } & Entendimento das matérias \\
\cline { 2 - 2 } & Adequação do conteúdo com o trabalho \\
\hline Motivos institucionais & Vocação pessoal \\
\hline Ausência de tutores nos polos & Aptidão para a profissão \\
\hline Acesso a bibliotecas & Possuir outro curso superior \\
\hline Estrutura dos polos de ensino & Adaptação ao sistema universitário \\
\hline
\end{tabular}




\begin{tabular}{|c|c|}
\hline Causas endógenas & Causas exógenas \\
\hline $\begin{array}{l}\text { Laboratório de informática nos polos de } \\
\text { ensino }\end{array}$ & $\begin{array}{l}\text { Mudança de interesse pessoal ou } \\
\text { profissional }\end{array}$ \\
\hline Interatividade no AVA & Estar cursando paralelamente outro curso \\
\hline $\begin{array}{l}\text { Meios de comunicação oferecidos para } \\
\text { contato }\end{array}$ & $\begin{array}{l}\text { Desconhecimento prévio a respeito do } \\
\text { curso de Administração a distância }\end{array}$ \\
\hline \multicolumn{2}{|l|}{ Tecnologia inadequada utilizada } \\
\hline Requisitos didático-pedagógicos & Características individuais \\
\hline Carga horária curricular do curso & Problemas de saúde \\
\hline Relação do currículo com o mercado & $\begin{array}{l}\text { Atendimento do curso às expectativas } \\
\text { prévias }\end{array}$ \\
\hline Critérios de avaliação do aluno & $\begin{array}{l}\text { Dificuldade de assimilação da cultura de } \\
\text { EaD }\end{array}$ \\
\hline Associação entre a teoria e a prática & Falta de habilidade para usar as TIC \\
\hline Relação entre conteúdos das disciplinas & Conjunturais \\
\hline Encontros presenciais & Problemas financeiros \\
\hline Complexidade das atividades & Influência familiar \\
\hline Contato entre colegas de cursos & Mudança de residência ou cidade \\
\hline $\begin{array}{l}\text { Reprovação em mais de duas disciplinas no } \\
\text { semestre }\end{array}$ & Mudança de estado civil \\
\hline Prazos de entrega das atividades & \multirow{6}{*}{$\begin{array}{l}\text { Responsabilidade econômica no sustento } \\
\text { da Família }\end{array}$} \\
\hline Avaliação dos exercícios & \\
\hline Avaliações das provas & \\
\hline Material didático oferecido & \\
\hline Qualidade do curso & \\
\hline Falha de elaboração do curso & \\
\hline
\end{tabular}

Fonte: Bittencourt e Mercado (2014).

O Quadro 2 contempla um amplo espectro de causas que podem influenciar na evasão dos cursos a distância. Salienta-se que o fator tempo, apontado pela maioria dos estudos como uma das causas salientes, enquadra-se como uma causa exógena, segundo a classificação dos autores.

Bizarra, Silva e Carneiro (2014) centram-se no papel do tutor em uma instituição de ensino superior púbica no Estado do Ceará. Por meio de um estudo qualitativo em que utilizam a análise de discurso, os autores concluem pela relação positiva entre o perfil do tutor nas suas dimensões pedagógica, acolhimento e motivacional e a redução da evasão.

Martins et al. (2013) estudaram a evasão no contexto dos cursos de licenciatura na Universidade Aberta do Brasil. Os autores apresentam um rol de motivos para justificar a evasão, conforme apresentado no Quadro 3. 
Quadro 3 - Motivos para evasão

\begin{tabular}{|l|c|}
\hline \multicolumn{1}{|c|}{ Motivo da evasão } & $\begin{array}{c}\text { Frequência percentual } \\
\text { da resposta }\end{array}$ \\
\hline Falta de tempo para os estudos & 39,3 \\
\hline Impossibilidade de participar de encontros presenciais & 19,5 \\
\hline Problemas pessoais ou de saúde & 16,8 \\
\hline Excesso de atividades semanais no curso & 12,3 \\
\hline Opção por mudança de curso & 11,2 \\
\hline Dificuldade com os conteúdos / curso difícil & 10,2 \\
\hline Curso ruim & 8,0 \\
\hline Inadequação com a modalidade EaD & 6,6 \\
\hline Problemas no acesso à Internet & 6,5 \\
\hline Dificuldade para lidar com a tecnologia & 4,2 \\
\hline Não identificação com a área do curso & 1,8 \\
\hline Insatisfação com tutor/professor & 1,8 \\
\hline
\end{tabular}

Fonte: Martins et al. (2013, p. 11).

A relação de motivos para a evasão dos cursos a distância, conforme se observa dos Quadros 2 e 3, é bastante abrangente, contemplando causas de natureza institucional, pessoal, contextual, financeira, cognitiva, entre outras.

Biazus (2004) oferece outra categorização para agrupar as causas da evasão: causas internas, externas e relacionadas ao aluno. Segundo o autor,

as causas internas são referentes aos recursos humanos, a aspectos didático-pedagógicos e à infraestrutura. Já as causas externas são ligadas a aspectos sócio-político-econômicos, e as causas relacionadas ao aluno são aquelas referentes à vocação e a outros problemas de ordem pessoal (BIAZUS, 2004, p. 79).

Abbad, Carvalho e Zerbini (2006) estudaram a evasão em cursos gratuitos oferecidos em nível nacional, concluindo por uma relação positiva entre evasão e a não utilização dos recursos disponibilizados pelo curso, tais como mural de notícias, chats e mensagens eletrônicas.

Assim como em outros estudos, o Censo EaD.BR (AsSociação BrASILEIRA DE EdUCAÇÃo A DISTÂNCIA, 2013, p. 99-100) aponta, como principais causas da evasão 
dos cursos corporativos livres, a falta de tempo e o acúmulo de atividades no trabalho, sendo que essa última causa termina por estar associado à falta de tempo para se dedicar ao curso. A ausência do tempo surge como principal motivador da evasão para todas as formas de cursos a distância, segundo o Censo EaD. BR.

Para Farias, Alcântara e Goia (2008), considera-se evadido o aluno que, após ter se matriculado, não completou o curso e desistiu, seja antes de iniciar o curso ou durante o seu desenvolvimento. Esse foi o conceito de evasão adotado na presente pesquisa.

Alguns dos motivos elencados como indutores da evasão não se aplicam aos cursos oferecidos pela UCS/Sefaz, nem a cursos oferecidos por organizações públicas a seus servidores. Por exemplo, não se aplicam os motivos relacionados ao custo de matrícula e mensalidades, pois os cursos são gratuitos; o desemprego, uma vez que os funcionários públicos gozam de estabilidade; dificuldades relacionadas aos polos de EaD, pois os cursos podem ser acessados de casa ou das estações de trabalho. Tais singularidades despertam ainda mais o interesse em compreender as causas da evasão nos cursos a distância oferecidos pela UCS/Sefaz .

Os níveis de evasão variam com o tipo de curso, conforme se observa do Quadro 4, que apresenta o índice médio de evasão por tipo de curso.

\section{Quadro 4 - Níveis de evasão da EaD}

\begin{tabular}{|l|c|}
\hline \multicolumn{1}{|c|}{ Tipos de curso } & Índice médio de evasão \% \\
\hline Cursos regulamentados totalmente a distância & 19,06 \\
\hline Cursos regulamentados semipresenciais & 14,83 \\
\hline Disciplinas EaD de cursos presenciais regulamentados & 10,49 \\
\hline Cursos livres corporativos & 17,98 \\
\hline Cursos corporativos & 14,62 \\
\hline
\end{tabular}

Fonte: Censo EaD. BR (Associação Brasileira de Educação A Distância, 2013, p. 98).

Observa-se, a partir do Quadro 4, que o índice médio de evasão para os cursos corporativos, tipo em que se enquadram os cursos da UCS/Sefaz, é de 14,62\%. 0 índice da evasão dos cursos oferecidos pela UCS/Sefaz para o período estudado, primeiro semestre do ano de 2014 , foi de $37 \%$, alto se comparado com o índice apresentado no Quadro 4. Dados como esse sugerem que outras variáveis podem estar induzindo a evasão. Diante dessa e de outras lacunas ainda existentes na compreensão da evasão dos cursos a distância, conforme sugerem Abbad, Zerbini e Souza (2010), principalmente na educação corporativa, desenvolveu-se a presente pesquisa, que tem por objetivo identificar o efeito da carga horária do curso, do gênero, da idade, da localização do aluno e do cargo (carreira da Sefaz ou carreira administrativa) na evasão dos cursos a distância oferecidos pela UCS/Sefaz. 


\section{Procedimentos metodológicos}

Os procedimentos metodológicos descrevem as etapas e as técnicas empregadas no estudo. Considerando-se o método quantitativo de abordagem, empregouse a regressão logística múltipla como forma de explicar o efeito das variáveis independentes sobre a evasão (variável dependente). A regressão logística, segundo Mesquita (2014, p. 13), "caracteriza-se por descrever a relação entre uma variável dependente qualitativa binária, associada a um conjunto de variáveis independentes qualitativas ou métricas". Constitui-se, prossegue o autor, "em uma poderosa ferramenta de análise quando se tem uma variável dependente qualitativa, podendo ser aplicada nas mais diversas áreas" (MESQUITA, 2014, p. 13).

$\mathrm{Na}$ EaD alguns estudos recentes têm utilizado a regressão logística para estabelecer relações entre variáveis, a exemplo de Walter e Abbad (2008); Sales, Abbad e Rodrigues (2011); Fiúza (2012); e Mequita (2014).

Utilizou-se neste estudo a regressão logística múltipla, técnica indicada quando a variável dependente - no caso estudado, a evasão - é dicotômica (HAIR et al., 2009). Sales, Abbad e Rodrigues (2011) utilizaram a regressão logística para investigar a situação do aluno ao final do curso - concluinte ou evadido -, sendo essa a variável dependente, tomando-se como variáveis independentes o desempenho do tutor, o desenho do curso, a disciplina e interesse do aluno, a experiência e habilidades importantes para EaD, o tempo disponível para o curso, o apoio no trabalho e questões familiares.

No estudo aqui apresentado tem-se, assim como Sales, Abbad e Rodrigues (2011), a evasão como variável dependente. Na codificação da variável dependente adotou-se 1 (um) para evasão e 0 (zero) para não evasão (concluinte). As variáveis independentes não numéricas também foram codificadas conforme se apresenta no Quadro 5.

\section{Quadro 5 - Codificação das variáveis independentes}

\begin{tabular}{|l|l|c|}
\hline Variável & Codificação & 1 \\
\hline \multirow{3}{*}{ Cargo } & Carreira da Sefaz & 0 \\
\cline { 2 - 3 } & Carreira Administrativa & 1 \\
\hline \multirow{3}{*}{ Local } & Capital & 0 \\
\hline \multirow{2}{*}{ Gênero } & Interior & 1 \\
\hline
\end{tabular}

Fonte: Elaboração própria. 
A relação entre as variáveis independentes e a variável dependente pode ser representada por meio de um modelo de análise, a partir do qual se extraem as hipóteses do estudo.

Adotando-se os mesmos princípios utilizados por Walter e Abbad (2008); Sales, Abbad e Rodrigues (2011); Fiúza (2012) e Mequita (2014), aplicou-se nessa pesquisa a regressão logística, cujo modelo de análise, hipóteses, descrição da amostra e da técnica estatística empregada são apresentados a seguir.

\section{Modelo de análise e hipóteses}

A fim de se alcançar o objetivo da pesquisa, adotou-se o modelo de análise conforme apresentado na Figura 2.

\section{Figura 2 - Modelo de análise}

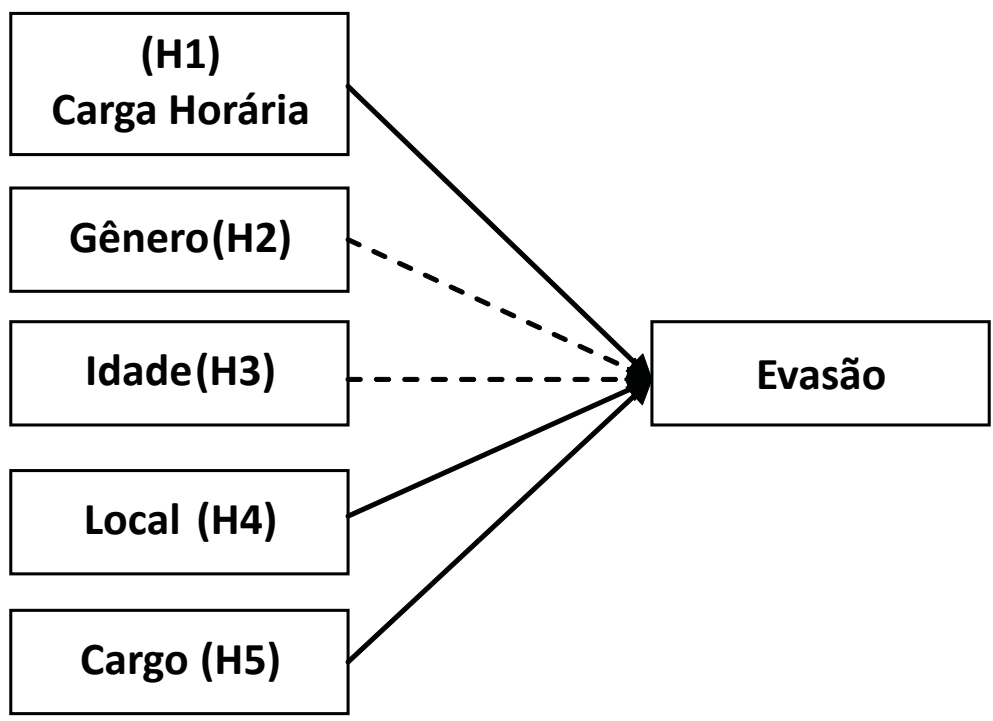

Fonte: Elaboração própria.

No modelo de análise apresentado na Figura 2, as linhas contínuas supõem relações significativas das variáveis independentes sobre a variável dependente, e as linhas tracejadas supõem uma relação não significativa. Assim sendo, estabelecemse as seguintes hipóteses:

H1: Cursos com carga horária maior exercem influência significativamente positiva na evasão.

Cargas horárias maiores exigem que o aluno se dedique por mais tempo ao curso, incorrendo em um dos motivos mais citados para justificar os altos índices de evasão (Coelho, 2003; AlmeidA, 2007; AbBAd; ZerbinI; SouZA, 2010; BitTencourt; 
MERCADO, 2014; MARTINS et al., 2013), portanto, é razoável supor-se que cursos com maiores cargas horárias influenciem positivamente na evasão.

H2: O gênero não exerce influência significativa sobre a evasão.

Os estudos que têm investigado a variável gênero como preditora da evasão de curso a distância não têm encontrado resultados conclusivos que permitam estabelecer uma relação causal entre gênero e evasão. Sales, Abbad e Rodrigues (2011); Martins e Hokari (2011), por exemplo, relatam vários estudos em que alguns afirmam haver uma relação entre gênero feminino e evasão, outros relatam uma relação entre gênero masculino e evasão e outros, ainda, relatam não haver relação alguma.

H3: A idade não exerce influência significativa sobre a evasão.

Assim como ocorre com o gênero, a variável idade tem apresentado resultados inconclusivos. Na revisão de literatura feita por Sales, Abbad e Rodrigues (2011, p. 4), os autores concluem que "em algumas pesquisas houve maior evasão entre alunos mais jovens, em outras, maior evasão entre alunos mais velhos e em outras não havia influência da idade do estudante sobre a evasão". Considerando o contexto do estudo, EaD no âmbito do ensino corporativo público, e o contexto da amostra, como se verá mais adiante, parece ser razoável supor-se que a idade não exerce influência significativa sobre a evasão.

H4: A localização do aluno exerce influência significativa sobre a evasão.

Por localização do aluno nesta pesquisa, segmentou-se aqueles que se encontram no interior do estado e aqueles que se encontram na capital. Na revisão de literatura, não se identificaram estudos que tivessem investigado o efeito da variável localização do aluno sobre a evasão. Há que se considerar que indivíduos localizados no interior do estado podem enfrentar alguns problemas com relação à tecnologia e acesso à internet, o que pode levar a um incremento na evasão. Conforme relatado por Martins et al. (2013), fatores como dificuldades para lidar com a tecnologia, falta de apoio acadêmico e/ou administrativo, limitação pessoal e problemas de acesso à internet são motivos sistematicamente relatados que se associam ao incremento da evasão. Considerando-se que, no interior do estado, esses fatores podem ser potencializados, admite-se como hipótese que alunos localizados no interior do estado estão mais propensos à evasão.

H5: O cargo exerce influência significativa sobre a evasão.

Para este estudo, considerou-se o cargo de ocupantes do grupo carreira da Sefaz (auditor fiscal e agente de tributos estaduais) e carreira administrativa, outras carreiras existentes na Sefaz/BA, que se constituem como público dos cursos a distância oferecidos. Da amostra estudada, 33\% dos integrantes do grupo carreira administrativa possuem no mínimo graduação, enquanto que $72 \%$ dos 
integrantes do grupo carreira da Sefaz possuem no mínimo graduação, indicando que os integrantes do grupo carreira da Sefaz possuem um grau de qualificação ou escolaridade superior aos integrantes do grupo carreira administrativa. Estudos têm relatado uma relação entre grau de escolaridade e evasão, apontando que níveis menores de instrução se relacionam ao aumento da evasão (COELHO, 2003; VARGAS, 2004). Assim sendo, parece ser razoável supor que a variável cargo apresente uma relação significativa com a evasão, associando-se a evasão com integrantes do grupo carreira administrativa.

\section{Descrição da amostra e coleta de dados}

A amostra foi composta por 530 servidores da Sefaz-BA, dentre uma população de aproximadamente 2.600 servidores, composta por integrantes do grupo carreira da Sefaz e carreira administrativa. Os dados foram coletados durante o primeiro semestre do ano de 2014 com base nos registros dos servidores inscritos nos cursos a distância oferecidos pela UCS/Sefaz e disponibilizados no AVA por meio da plataforma Moodle. Do total de servidores inscritos, 45,5\% são do gênero feminino, $49,5 \%$ localizam-se na capital do estado, $73,4 \%$ são da carreira da Sefaz e $61 \%$ possuem no mínimo graduação. Os dados foram analisados com o auxílio do pacote estatístico Statistical Package for the Social Scienc (SPSS) ${ }^{2}$, versão 21.

\section{Resultados}

Os resultados foram apresentados em duas etapas. Na primeira etapa, apresentase a estatística descritiva da amostra e, na segunda etapa, apresenta-se o resultado da regressão logística.

A Tabela 1 apresenta o resultado da estatística descritiva da amostra composta pelos 530 servidores.

Tabela 1 - Estatística descritiva

\begin{tabular}{cccccccc}
\hline \multicolumn{2}{c}{ Evasão \% } & \multicolumn{2}{c}{ Gênero \% } & \multicolumn{2}{c}{ Local \% } & \multicolumn{2}{c}{ Cargo \% } \\
\hline \multirow{2}{*}{ Sim } & Não & $\begin{array}{c}\text { Femi- } \\
\text { nino }\end{array}$ & $\begin{array}{c}\text { Mascu- } \\
\text { lino }\end{array}$ & Capital & Interior & $\begin{array}{c}\text { Carreira } \\
\text { Sefaz }\end{array}$ & $\begin{array}{c}\text { Carreira } \\
\text { administra- } \\
\text { tiva }\end{array}$ \\
37 & 63 & 45,5 & 54,5 & 49,4 & 50,6 & 73,4 & 26,6 \\
\hline
\end{tabular}

Fonte: Elaboração própria.

2 O SPSS é um software estatístico amplamente utilizado em pesquisas quantitativas. Para informações mais aprofundadas sobre aplicações do SPSS e conceitos estatísticos, consultar Bruni (2012). 
Observa-se da Tabela 1 que 37\% dos inscritos evadiram-se, taxa considerada alta quando compara com o Censo EaD. BR (AsSOCIAÇÃo BRASILEIRA DE EDUCAÇÃo A DISTÂNCIA, 2013) para os cursos corporativos, cuja taxa se situa em 14,62\%. Por outro lado, Abbad, Zerbini e Souza (2010) citam dados do Instituto Monitor (2007), apontando que 59,3\% das empresas registraram evasão de até $20 \%$, 18,5\% das empresas registraram evasão entre $20 \%$ e $30 \%$, e $22,2 \%$ das empresas registraram evasão superior a 30\%. Em 2008, prosseguem os autores, 55\% de uma amostra composta por 41 empresas registraram evasão superior a $30 \%$.

O gênero e o local não apresentam grandes diferenças. Na amostra existe uma forte predominância de integrantes do grupo carreira da Sefaz (auditores fiscais e agentes de tributos estaduais).

A idade média dos servidores da amostra foi de 53 anos, variando de 18 a $73^{3}$ anos. Esse dado encontra-se em linha com Abbad, Zerbini e Souza (2010), que apontam uma grande amplitude nas idades de alunos de cursos a distância, variando entre 18 e 60 anos, com predomínio de pessoas em idades entre 30 e 60 anos.

A carga horária dos cursos situa-se entre 12 e 60 horas aula, conforme apresentado na Tabela 2.

Tabela 2 - Carga horária percentual dos cursos

\begin{tabular}{ccccccc}
\hline \multicolumn{7}{c}{ Carga horária percentual dos cursos } \\
\hline $\begin{array}{c}\text { Carga } \\
\text { Horária }\end{array}$ & 12 & 16 & 20 & 24 & 30 & 60 \\
Percentual & 18 & 21 & 27 & 19 & 6 & 9 \\
\hline
\end{tabular}

Fonte: Elaboração própria.

A Tabela 2 mostra que a maior porcentagem de cursos, $27 \%$, possui uma carga horária de 20 horas. Os cursos de maior carga horária possuem 60 horas. A porcentagem acumulada de cursos até 24 horas chega a $85 \%$. Abbad, Zerbini e Souza (2010) relatam uma carga horária média de cursos de 45 horas, variando de 8 a 255 horas. A baixa carga horária dos cursos oferecidos pela Sefaz/BA pode ter contribuído para a não significância dessa variável sobre a evasão.

\footnotetext{
${ }^{3}$ A amostra possui dois servidores com idade acima de 70 anos. Trata-se de cargos de confiança (não concursados), não alcançados pela aposentadoria compulsória.
} 
Os resultados da regressão logística são apresentados na Tabela 3.

Tabela 3 Resultados da regressão logística

\begin{tabular}{ccccccc}
\hline Variáveis & B & S.E. & Wald & df & Sig. & Exp(B) \\
\hline CH &, 004 &, 007 &, 384 & 1 &, 536 & 1,004 \\
Gênero(1) &, 086 &, 200 &, 185 & 1 &, 667 & 1,090 \\
Idade &,- 009 &, 012 &, 621 & 1 &, 431 &, 991 \\
Local(1) &,- 585 &, 204 & 8,246 & 1 &, 004 &, 557 \\
Cargo(1) &, 199 &, 243 &, 670 & 1 &, 413 & 1,220 \\
Constante &,- 054 &, 662 &, 007 & 1 &, 935 &, 948 \\
\hline
\end{tabular}

Fonte: Elaboração própria.

A análise dos resultados da regressão permite afirmar que apenas a variável local exerce uma influência significativa para um grau de confiança de $95 \%$ sobre a evasão, a partir da significância (sig.) de 0,04. O sinal negativo do beta (B) implica que o impacto ocorre em função dos servidores que se encontram no interior do estado, ou seja, servidores situados no interior do estado exercem uma influência significativa na evasão. As demais variáveis investigadas, carga horária dos cursos, gênero, idade e cargo, não apresentaram significância estatística sobre a evasão. 0 resultado das hipóteses levantadas é apresentado no Quadro 6.

\section{Quadro 6 - Resultado das hipóteses}

\begin{tabular}{|c|c|}
\hline Hipótese & Resultado \\
\hline $\begin{array}{l}\text { H1: Cursos com carga horária maiores exercem influência significati- } \\
\text { vamente positiva na evasão. }\end{array}$ & Rejeitada \\
\hline H2: O gênero não exerce influência significativa na evasão. & Aceita \\
\hline H3: A idade não exerce influência significativa na evasão. & Aceita \\
\hline $\begin{array}{l}\text { H4: A localização do aluno exerce influência significativa sobre a } \\
\text { evasão. }\end{array}$ & Aceita \\
\hline H5: O cargo exerce influência significativa na evasão. & Rejeitada \\
\hline
\end{tabular}

Fonte: Elaboração própria.

A falta de tempo tem sido citada como um dos motivos mais fortes para justificar a evasão dos cursos oferecidos a distância, segundo Neves (2006), Ramminger (2006) e Almeida (2007). Comarella (2009), por exemplo, afirma na 
sua dissertação que aproximadamente $69 \%$ dos indivíduos pesquisados alegaram falta de tempo como fator determinante da evasão. Com relação à hipótese $\mathrm{H} 1$, era de se esperar que cursos de maior duração exercessem influência significativa na evasão, haja vista que demandam maior tempo de dedicação, contudo, os resultados indicam, para a amostra pesquisada, que a carga horária do curso não influencia no índice de evasão. Possivelmente a baixa carga horária dos cursos em geral ofertados pela UCS/Sefaz tenha contribuído para a não significância dessa variável. $\mathrm{O}$ gênero $(\mathrm{H} 2)$ e a idade $(\mathrm{H} 3)$ não exerceram influência significativa sobre a evasão, confirmando achados de estudos anteriores e as hipóteses testadas. O cargo (H5) não apresentou significância, rejeitando-se a hipótese de que integrantes da carreira administrativa exerceriam influência expressiva sobre a evasão. A localização do aluno (H4), por sua vez, apresentou resultados significativos, evidenciando a influência da localização no índice de evasão. Tal achado pode estar associado a outros fatores de evasão, como, por exemplo, a falta de apoio acadêmico, problemas com a tecnologia, falta de apoio administrativo (ALMEIDA, 2007).

\section{Considerações finais}

Buscou-se, com este artigo, investigar, por meio de regressão logística múltipla, a significância da carga horária do curso, do gênero, da idade, do local onde se encontra o aluno (capital ou interior) e do cargo (carreira da Sefaz ou carreira administrativa) sobre a evasão dos cursos EaD oferecidos pela Universidade Corporativa dos Servidores Públicos da Secretaria da Fazenda do Estado da Bahia aos seus servidores.

Uma análise preliminar da amostra pesquisada indicou um elevado índice de evasão, compatível com os achados de outros estudos. Também em linha com outros estudos, o gênero e a idade não apresentaram relação significativa com a evasão. Quanto ao cargo, embora se observe uma forte predominância de servidores de carreira da Sefaz como público do $\operatorname{EaD}(73,4 \%$ do total), estatisticamente a variável não apresentou influência significativa sobre a evasão. A carga horária do curso também não exerceu influência significativa sobre a evasão, possivelmente devido ao fato de que a maior concentração dos cursos se situe em uma faixa de baixa carga horária (cursos de até 24 horas concentram 85\% do total).

O estudo apontou significância estatística na localização do aluno, sugerindo que alunos situados no interior do estado evadem-se mais dos cursos do que os alunos situados na capital. Esse achado de pesquisa possibilita a adoção de medidas 
direcionadas a esse público específico, com vistas a compreender os motivos da evasão e empreender ações para reduzi-la.

Sugere-se, como agenda de pesquisa, o aprofundamento da investigação, com pesquisas qualitativas direcionadas aos servidores localizados no interior do estado, com o objetivo de identificar os motivos da elevada evasão nesse público; e a ampliação da investigação, por meio de estudos quantitativos em outras unidades de ensino corporativo público em outros estados, a fim de se verificar a extensão dos achados de pesquisa aqui relatos.

\section{Referências bibliográficas}

AbBAd, G. da S.; ZerbinI, T.; SouZA, D. B. L de. Panorama das pesquisas em educação a distância no Brasil. Estudos de Psicologia, v. 15, n. 3, p. 291-298, 2010.

AbBAd, G. da S.; CARVAlho, R.; ZerbiNI, T. Evasão em curso via Internet: explorando variáveis explicativas. $R A E$ - eletrônica, v. 5, n. 2, 2006.

Associação Brasileira de Educação a Distância (ABed). Censo EaD.BR 2013. Relatório analítico da aprendizagem a distância no Brasil. Curitiba: Ibpex, 2014.

ALMEIDA, O. C. de S. Evasão em cursos a distância: fatores influenciadores. Revista Brasileira de Orientação Profissional, v. 14, n. 1, p. 19-33, 2013.

Evasão em cursos a distância: validação de instrumento, fatores influenciadores e cronologia da desistência. Brasília: UnB, 2007. Dissertação de Mestrado - Universidade de Brasília, Brasília, 2007.

Alves, A. P. V.; SALES, S. B. A evasão escolar na modalidade de ensino a distância: o polo presencial de Itapemirim - ES. In: SIMPÓSIO INTERNACIONAL DE EDUCAÇÃo A Distância (SIED); EnContro de Pesquisadores de Educação a DistÂncia (ENPED), 10 a 22 de Setembro de 2012, São Paulo. Anais... São Paulo, 2012.

BAHIA. Decreto no 9.533, de 31 de agosto de 2005. Altera dispositivos do Regimento da Secretaria da Fazenda, e cria a Universidade Corporativa do Serviço Público Unidade SEFAZ. Diário Oficial do Estado da Bahia, Poder Executivo, Salvador, BA. 2005.

BIAZUS, C. A. Sistema de fatores que influenciam o aluno a evadir-se dos cursos de graduação na UFSM e na UFSC: um estudo no curso de Ciências Contábeis. 2004 152 f. Tese (Doutorado) - Programa em Engenharia de Produção, Universidade Federal de Santa Catarina, 2004.

Bittencout, I. M.; Mercado, L. P. L. Evasão nos cursos na modalidade de educação a distância: estudo de caso do Curso Piloto de Administração da UFAL/UAB. Ensaio: Aval. Pol. Publ. Educ., Rio de Janeiro, v.22, n. 83, p. 465-504, abr./jun. 2014.

BizarriA, F. P. de A.; Silva, M. A. da; CARneiro, T. C. J. Evasão discente na EAD: percepções do papel do tutor em uma instituição de ensino superior. In: CoNGRESSO BRASILEIRO DE ENSINO SUPERIOR A DISTÂNCIA (Esud), 11.,05 a 08 de Agosto de 2014, Florianópolis. Anais... Florianópolis-SC, 2014. 
BRASIL. Decreto no 5.622, de 19 de dezembro de 2005. Regulamenta o art. 80 da Lei $n$ o 9.394, de 20 de dezembro de 1996, que estabelece as diretrizes e bases da educação nacional. Diário Oficial da União. Disponível em Portal do Ministério da Educação <https://legislacao.planalto.gov.br/legisla/legislacao.nsf/viwTodos/ 10770C26E62A9CD0032570DD004269DB?OpenDocument\&HIGHLIGHT=1 >. Acesso em: 9 de jul. de 2011.

BRUNI, A. L. Spss: Um guia prático para pesquisadores. São Paulo: Atlas, 2012.

Bruno-FARIA, M. de F.; Franco, A. L. Causas da evasão em curso de graduação a distância em Administração em uma universidade pública federal. Rev. Teoria $e$ Prática da Educação, v. 14, n. 3, p. 43-56, set./dez. 2011.

Coelho, M. L. A. Formação continuada do docente universitário em cursos a distância via Internet: um estudo de caso. Belo Horizonte: Abed, 2003. Disponível em: < http://www.abed.org.br/seminario2003/texto06.htm.>. Acesso em: 18 mar. 2015.

Comarella, R. L. Educação superior a distância: evasão discente. 2006. 146 f. Dissertação (Mestrado em Engenharia e Gestão do Conhecimento) - Universidade Federal de Santa Catarina, Florianópolis, SC, 2009.

FARIAS, L.; AlCANTARA, V.; GoIA, C. Índice e causa de evasão na modalidade a distância em cursos de graduação: uma ferramenta para gestão. 2008. Disponível em: <http://200.169.53.89/download/CD\%20congressos/2008/V\%20ESUD/trabs/ t38898.pdf. >. Acesso em: 15 mar. 2015.

FIUZA, P. J. Adesão e permanência discente na educação a distância: investigação de motivos e análise de preditores sociodemográficos, motivacionais e de personalidade para o desempenho na modalidade. 2012. $145 \mathrm{f}$. Tese (Doutorado em Psicologia) - Instituto de Psicologia, Universidade Federal do Rio Grande do Sul, Porto Alegre, RS, 2012.

Gonzalez, R. A.; Silva, A. A. da. O ensino a distância na Secretaria da Fazenda do Estado da Bahia. 2013. In: CongResso LATINo AMERICANO DAS ESCUELAS DE AdMinistración (Cladea), 48., 2013, Rio de Janeiro. Anais... Rio de Janeiro, 2013.

HAIR, J. F. et al. Análise multivariada de dados. Trad. Adonai S. Sant'Anna e Anselmo Chaves Neto. 6. ed. Porto Alegre: Bookman, 2009.

Johnson, J. D. Gestão de redes de conhecimento. Trad. Janaína Marcoantonio. São Paulo: Editora Senac, 2011.

JORGE, B. G. et al. Evasão na educação a distância: um estudo sobre a evasão em uma instituição de ensino superior. In: CONGRESSO INTERNACIONAL DE EDUCAÇÃo A DistÂnCIA (Ciead), 16., 2010, Foz do Iguaçu. Anais... Foz do Iguaçu, PR, 2010.

LACERDA, F. K. D. de.; ESPÍNDOLA, R. de M. Evasão na educação a distância: um estudo de caso. Fundação Cecierj, Rio de Janeiro, v. 3, n.1, dez. 2013.

MARTINS, R. X. et al. Por que eles desistem? estudo sobre a evasão em cursos de licenciatura a distância. In: CONGRESSO BRASILEIRO DE ENSINO SUPERIOR A DISTÂNCIA (Esud), 10., 11 a 13 de Junho de 2013, Belém. Anais... Belém, PA, 2013.

MARTINS, R. X; HOKARI, A. Educação a distância é para todos? Um estudo exploratório 
sobre possíveis preditores do sucesso acadêmico. In: CONGRESSO BRASILEIRO DE ENSINO SUPERIOR A DISTÂNCIA (Esud), 8., 03 a 05 de Outubro de 2011, Ouro Preto. Anais... Ouro Preto, MG, 2011.

MESQUITA, P. S. B. Um modelo de regressão logística para avaliação dos programas de põs-graduação no Brasil. 2014. 90 f. Dissertação (Mestrado em Engenharia de Produção) - Centro de Ciência e Tecnologia. Laboratório de Engenharia de Produção, Universidade Estadual do Norte Fluminense Darcy Ribeiro, Campos dos Goytacazes, 2014.

Moran, José Manuel. O que é educação a distância. 2002. Disponível em: <http:// www.eca.usp.br/prof/moran/dist.htm>. Acesso em: 21 jan. 2015.

NEVES, Yára Pereira da Costa e Silva. Evasão nos cursos à distância: curso de extensão TV na Escola e os desafios de hoje. 2006. 97 f. Dissertação (Mestrado em Educação Brasileira) - Centro de Educação. Programa de Pós-Graduação em Educação Brasileira, Universidade Federal de Alagoas, Maceió, 2006.

Netto, C.; Guidotti, V.; SANTOS, P. K. A evasão na EaD: investigando causas, propondo estratégias. In: CONFERÊNCIA LATINO AMERICANA SOBRE EL ABANDONO EN LA EdUCACIÓn SUPERIOR (Clabes), 2., 08 e 09 de Novembro de 2012, Porto Alegre. Anais... Porto Alegre, 2012.

PolAnY, M. Personal knowledge: towards a post-critical phisophosy. Chicago: University of Chicago Press, 1974.

Pretto, N. L.; PICANçO, A. de A. Reflexões sobre EaD: concepções de educação. In: FREITAS, K, S. de; ARAúso, B. (Coords.). Educação a distância no contexto brasileiro: algumas experiências da UFBA. Salvador, BA: UFBA, 2005.

RAMMINGER, S. Do encontro ao desencontro: fatores relacionados à procura de cursos de EaD em Psicologia e posterior evasão. Dissertação (Mestrado em Educação) - PUC RS, Faculdade de Educação, 2006.

RAMOS, M. N. As universidades corporativas. Jornal da Ciência, Rio de Janeiro, SBPC, v. 14, n. 442, 2000.

Rıccıo, N. C. R. Educação a distância: uma alternativa para a UFBA? In: FreITAS, K. S. de; ArAúso, B. (Coords.). Educação a distância no contexto brasileiro: algumas experiências da UFBA. Salvador, BA: UFBA, 2005.

SAles, P. de A. O.; AbBAD, G.; Rodrigues, J. L. Variáveis preditivas de evasão e persistência em treinamentos a distância. In: ENCONTRO ANUAL DA ASSOCIAÇÃo Nacional de Programas de Pós-Graduação em Administração e Pesquisa (ENANPAD), 35., 2011, Rio de janeiro. Anais... Rio de Janeiro: Anpad, 2011.

SANTOS, Priscila K. Inclusão digital de professores: uma proposta de construção de trajetórias personalizáveis em cursos na modalidade a distância. 2012. 101 f. Dissertação (Mestrado em Educação) - Faculdade de Educação, Pontífica Universidade Católica do Rio Grande do Sul, Porto Alegre, 2012.

SILVEIRA, C. A. B. Educação a distância e a evasão: estudo de caso da realidade no polo UAB de Franca. In: SIMPósIo INTERNACIONAL DE EdUCAÇÃo A DISTÂNCIA (SIED); ENCONTRO DE PESQUISADORES DE EDUCAÇÃO A DISTÂNCIA (ENPED), 10 a 22 de Setembro de 2012. Anais... São Paulo, 2012. 
VARGAS, M. R. M; LIMA, S. M. V. Barreiras à implantação de programas de educação e treinamento a distância. In: Congresso Internacional de Educação a Distância, 11. , 07 a 10 de setembro de 2004, Salvador. Anais... Salvador, BA, 2004.

Walter, A. M.; ABBAD, G. da S. Variáveis preditoras de evasão em dois cursos a distância. In: Encontro ANuAl dA AsSociação NACIONAL de Programas de PósGraduação em AdMinistraçÃo E Pesquisa (ENANPAD), 32., 2008, Rio de janeiro. Anais... Rio de Janeiro: Anpad, 2008.

ZoRDAN, G. R. Estudo sobre os fatores que influenciaram a evasão no curso de Administração da UFMA, na modalidade a distância, no polo presencial de Porto Franco - MA. São Luis: Universidade Federal do Maranhão (UFMA), 2012. 105 f. Dissertação (Mestrado) - Programa de Pós-Graduação Interdisciplinar em Cultura e Sociedade, Universidade Federal do Maranhão, São Luis, 2012.

Ricardo Alonso Gonzalez

Doutorado em andamento pela Universidade Federal da Bahia (UFBA). É auditor fiscal da Secretaria de Fazenda do Estado da Bahia e professor universitário. Contato: ricardoalonsog5@gmail.com

Janicleide Gonçalves do Nascimento

Possui mestrado pela Fundação Visconde de Cairu. É analista técnico da Coordenação de Ensino Distância da Universidade Corporativa do Serviço Público, Unidade da Sefaz/BA. Contato: jani@sefaz.ba.gov.br

Luciana Barone Leite

É especialista em Metodologia e Didática do Ensino Superior pela Faculdade São Bento da Bahia. Atua como Coordenadora de EaD da Secretaria de Fazenda do Estado da Bahia. Contato: Ileite@sefaz.ba.gov.br 
RSP 